\title{
Mode of Delivery and Number of Children Effect on Sexual Function
}

\author{
Deha Denizhan Keskin ${ }^{1}$ \\ ${ }^{1}$ Department of Obstetrics and Gynecology, Ordu University of Medical Faculty.Ordu, Turkey \\ Received: 31 March 2018, Accepted: 04 April 2018, Published online: 20 April 2018 \\ (C) Ordu University Institute of Health Sciences, Turkey, 2018
}

\begin{abstract}
Objective: To reveal the effect of the delivery mode (vaginal delivery, cesarean delivery) and the number of children on sexual function.

Methods: Eightywomen who applied to our clinic for routine gynecological control between July 2017 and January 2018 were included in the study. Age of women's, parity, demographic analysis andArizona Sexual Experiences Scale (ASEX) were done. The patients were divided into four groups: group I only had one vaginal delivery, group II only one cesarean delivery, group III two/three vaginal deliveries, group IV two/three cesarean deliveries.

Results: We found significantly lower ASEX scores in the cesarean delivery andone child group $(\mathrm{p}=0,000)$. When the groups were examined; ASEX scores were respectively; I 14,45 - II 11,65 - III 17,35 - IV 14,15 $(p=0,000)$. Finally vaginal delivery and having more than one child has created a tendency to have female sexual dysfunction.

Conclusion: Even though we found in our study there is no clear evidence in the literature that cesarean delivery might be protective for the development of female sexual dysfunction. There is need of randomized, well-controlled, long-term studies. Sexual dysfunction is a relatively common health problem and efforts to recognize and treat this problem should not focus only on delivery mode.

Key words: Female sexual dysfunction, Mode of delivery, Number of children, ASEX.
\end{abstract}

Address for correspondence/reprints:

Deha Denizhan Keskin

Telephone number: +90 (452) 6112555 / 4905

E-mail: dehadenizhankeskin@gmail.com

DOI: $10.19127 / \mathrm{mbsjohs} .411483$

\section{Introduction}

Sexual health is an important part of the quality of life of women. World Health Organization has defined it as "a state of physical, emotional, mental and social well-being related to sexuality; it is not only the absence of disease, dysfunction or infirmity" (World Health Organization, 2012).

Pregnancy process, delivery, lactation period affects multiple physiological and mental functions that hinder sexuality. But the healthcare professionals tend to focus on topics related to vaginal trauma, operative vaginal delivery, episiotomy, cesarean delivery instead of physiological variations (Brtnicka et al., 2009).

Female sexual dysfunction (FSD) is one of themost common health problem. Although some clinicians say that FSD is seen up to $90 \%$, it seems to affect practically half of the women population (Fugl-Meyer, 2000; Kadri et al., 2002; Oberg et al., 
2004; Derogatis et al., 2008; Ghorat et al., 2017). Multifactorial situations in woman's life cycle such as aging, hormonal status, pregnancy releated status (delivery, puerperium, breastfeeding, perineal trauma), physiological and medical disorders determine the ratio of FSD (Von Sydow, 1999; West et al., 2008).

The literature researching the effects of pregnancy and delivery on postpartum sexual function is heterogeneous and inconclusive. But it's clear that FSD is seen more likely in postpartum period (Brown et al., 1998; Barrett et al., 2000; Signorello et al., 2001; DeJudicibus et al., 2002; Thompson et al., 2002; Ejegard et al., 2008; Klein et al., 2009; Boroumandfar et al., 2010).

Considering the World Health Organization recommendation that cesarean delivery rates should not be higher than 10 to $15 \%$ (World Health Organization, 1985), the cesarean rate is continuously and worryingly increasing in Turkey since the 1990's (Turkey Demographic and Health Survey, 2008). As the half of turkish obstetricans think that preference tendency might be related fewer effects of cesereanon sexual functions (Arikan et al., 2011). Notwithstanding unconvincing data on the relationship between mode of delivery and postpartum sexual dysfunction, in our study we aimed to reveal the effect of the delivery mode (vaginal delivery, cesarean delivery) and the number of children on sexual function

\section{Methods}

This prospective study received approval from the human research ethics commitee at the Ordu University Medical Faculty Research and Training Hospital. Participants were recruited from the gynecology clinic between July 2017 and January 2018. Eighty healthy women who applied to our clinic for routine gynecological control were included in the study. The exclusion criteria were as follows: chronic disease, poor obstetric history (macrosomic birth, stillbirth, shoulder dystocia, advanced genital tract injury), comorbid conditions in pregnancy (gestational diabetes, gestational hypertension/preclampsia, thyroid dysfunction), gynecologic pathology that may have an impact on sexual function (such as vaginitis, pelvic inflammatory disease, chronic pelvic pain, myoma, adnexal mass). More than three children women were exculded too.

Age of women's, parity, demographic analysis was done. There are severel index and scale for evaluating sexual function. We administered
Arizona Sexual Experiences Scale (ASEX). The ASEX was selected for use in this study as a well validated 5-item questionnaire that is psychometrically sound and easy to self-adminester. The ASEX scores are between 5 and 30. High scores are associated with sexual dysfunction (McGahuney et al., 2000).

The patients were divided into four groups: group I only had one vaginal delivery, group II only one cesarean delivery, group III two / three vaginal deliveries, group IV two / three cesarean deliveries.

Statistical analyses were performed with the SPSS 20 programme. Compairing the four groups One Way Anova analysis was used.

\section{Results}

Eighty women were recruited for this study. All of them completed the demografic analysis and ASEX. The mean age of the women was $36,66+6,35$ (18-45).

The average ASEX score was 14,4.We found significantly lower ASEX scores in the cesarean delivery group $(\mathrm{p}=0,000)$. The mean ASEX score was 12,9 in the casarean delivery group whereas 15,9 in the vaginal delivery group.

In the group with one child, ASEX scores were significantly lower too $(\mathrm{p}=0,000)$. The mean ASEX score was 13,05 in the one child group while it was 15,75 in the more than one child group.

When four groups were compared we also found a significant difference between the ASEX scores. The mean ASEX scores were respectively; I 14,45 II 11,65 - III 17,35 - IV 14,15 ( $\mathrm{p}=0,000)$.

Mode of delivery, number of children, and four group results are shown figure 1,2 and 3

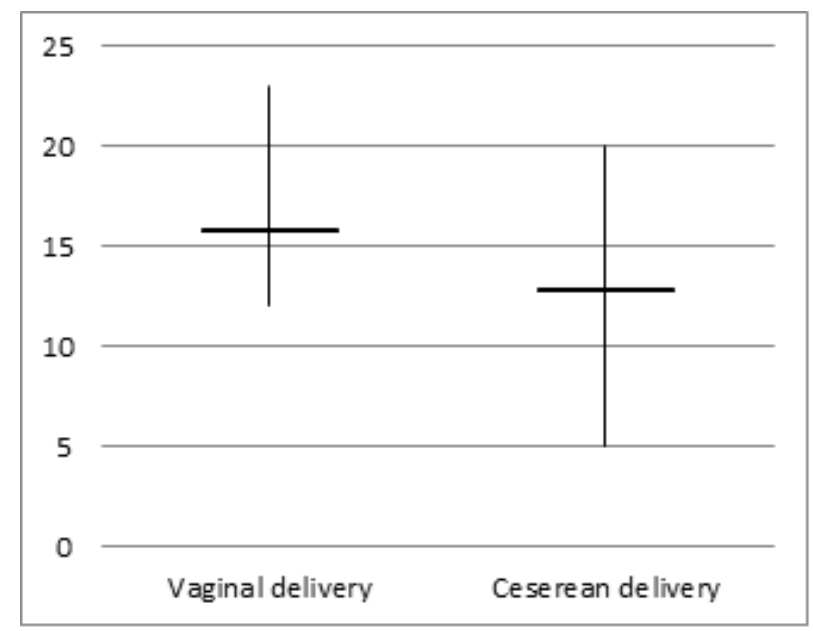

Figure 1. ASEX Skorları 


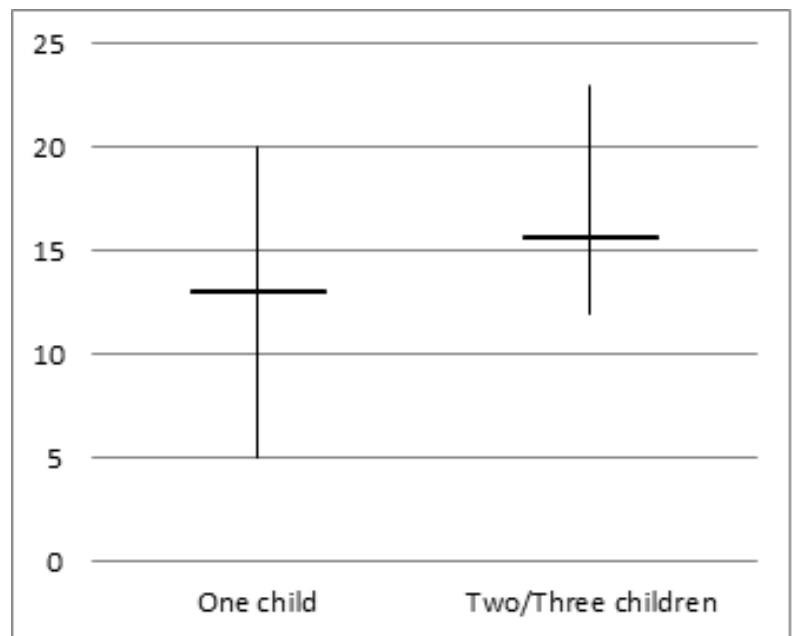

Figure 2. ASEX Skorları

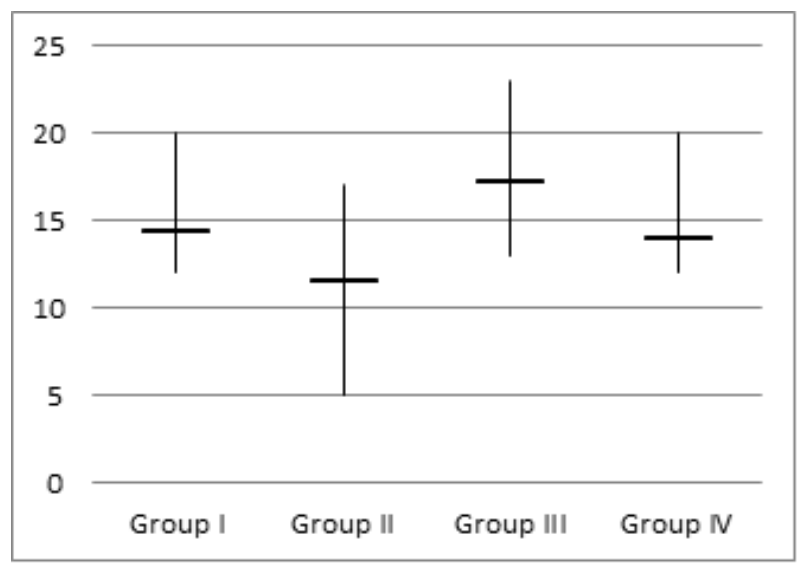

Figure 3. ASEX Skorları

Abstractly vaginal delivery and having more than one child has created a tendency to have FSD. This might be releated with neuromuscular vaginal trauma and longer breastfeeding period. And also fatigue, postpartum depression, body image is prominent.

\section{Discussion}

Female sexual dysfunction is an ignored tabu yet it is also very common and reducing the quality of life. Although many women reported problems with sexual intercourse, only approximately $10 \%$ felt the need to seek help or advice (Glazener, 1997).

There is conflicting evidence about the role of delivery mode and number of children on sexual health outcomes. The literature is very heterogeneous and debateble. A good many of studies reported no significant relationship between delivery mode and sexual dysfunction (Barrett et al., 2000; Klein et al., 2009; Hannah et al., 2004; Woranitat et al., 2007; Connolly et al., 2005; Pauls et al., 2008; Gungor et al., 2007; Shirvani et al.,
2010; Hannah et al., 2002; Hosseini et al., 2012; Fan et al., 2017; Saydam et al., 2017; Gun et al., 2016; Ghorat et al., 2017; Rezaci et al., 2017). Despite that some studies like our study found significant relation between them (Griffiths et al., 2006; Chang et al., 2010).

Klein et al. found that women with an intact perineum or perineal tears had less sexual dysfunction comparison with perineal trauma. Dean et al. reported that cesarean delivery was associated with better vaginal tone yet not releated to good sexual function. Kahramanoglu et al. revealed that caesarean section was not superior to vaginal birth and irrespective of their type of delivery, sexual function 6 months after childbirth was similar to prepregnancy scores.

Rathfisch et al. and Baksu at al. focused on episiotomy and found relation beetween episiotomy and sexual dysfunction. In another episiotomy study Gun et al. reported the relationship between the degree of perineal laceration and postpartum dyspareunia and observed that there was still not a clear evidence to say episiotomy is an etiologic factor on sexual dysfunction in the long term.

Brown at al. and Thompson et al. had studies about relation between pain and sexual dysfunction. They reported that noncomplicated vaginal delivery was not associated with sexual dysfunction but operative vaginal delivery which had higher pain was related with sexual dysfunction.

\section{Conclusion}

Delivery mode and number of children have a significant impact on the quality of sexual life and should be paid more attention. On the other hand, there is need of randomized, well-controlled, longterm studies. Yet it is hard for ethical reasons and less patient acceptance. But well-designed, large simple sized studies will contribute the literature.

When we look the literature there is no clear evidence that cesarean delivery might be protective for the development of female sexual dysfunction. Even though we found in our study; having vaginal delivery and more than one children group of women has worse sexual function than cesarean delivery and single children group. Forwhy there are lots of variables in the etiology of sexual dysfunction, not only delivery mode and number of children. Because of this reason sexual dysfunction is a relatively common health problem and efforts to recognize and treat this problem should not focus only on delivery mode. 
Ethics Committee Approval: The requirement for the ethics committee approval was waived for the retrospective design and valid legal regulations at the time of the study.

Peer-review: Externally peer-reviewed.

Author Contributions: Idea- D.D.K.; Design D.D.K.; Supervision- D.D.K.; Funding- D.D.K.; Materials- D.D.K.; Data Collection/Data ProcessD.D.K., Analyze or Comment- D.D.K., Literature Scanning- D.D.K.; Writer of Paper- D.D.K.; Critical Review- D.D.K.

Conflict of Interest: No conflict of interest was declared by the author.

Financial Disclosure: The author declared that this study has received no financial support.

\section{References}

Arikan DC, Coskun A, Kiran H. Turkish obstetricians' personal preference for mode of delivery and attitude toward cesarean delivery on maternal request. Archives Gynecology Obstetrics, 2011; 284: 543-549.

Baksu B, Davas I, Agar E, Akyol A, Varolan A. The effect of mode of delivery on postpartum sexual functioning in primiparous women. International Urogynecology Journal of Pelvic Floor Dysfunction, 2007; 184: 401-406.

Barrett G, Pendry E, Peacock J, Victor C, Thakar R, Manyonda I. Women's sexual health after childbirth. British Journal of Obstetrics and Gynaecology, 2000; 107: 186-195.

Boroumandfar K, Rahmati MG, Farajzadegan Z, Hoseini $H$. Reviewing sexual function after delivery and its association with some of the reproductive factors. Iranian Journal of Nursing and Midwifery Research, 2010; 15: 220-223.

Brown S, Lumley J. Maternal health after childbirth: results of an Australian population based survey. British Journal of Obstetrics and Gynaecology, 1998; 105: 156-161.

Brtnicka H,Weiss P, Zverina J. Human sexuality during pregnancy and the postpartum period. Bratislava Medical Journal, 2009; 110: 427-431.

Chang SR, Chang TC, Chen KH, Lin HH. Sexual function in women 3 days and 6 weeks after childbirth: a prospective longitudinal study using the Taiwan version of the Female Sexual Function Index. Journal of Sexual Medicine, 2010; 7: 12: 3946-3956.

Connolly A, Thorp J, Pahel L. Effects of pregnancy and childbirth on postpartum sexual function: A longitudinal prospective study. International Urogynecology Journal, 2005; 16: 263-267.

Dean N, Wilson D, Herbison P, Glazener C, Aung T, Macarthur C. Sexual function, delivery mode history, pelvic floor muscle exercises and incontinence: A cross-sectional study six years postpartum. Australian and New Zealand Journal of Obstetrics and Gynaecology, 2008; 48: 302311.

DeJudicibus MA, McCabe MP. Psychological factors and the sexuality of pregnant and postpartum women. Journal of Sex Research, 2002; 39: 94-103.

Derogatis LR, Burnett AL. The epidemiology of sexual dysfunctions. Journal of Sexual Medicine, 2008; 5: 2: 289-300.

Ejegard H, Ryding EL, Sjogren B. Sexuality after delivery with episiotomy: a long-term follow-up. Gynecologic and Obstetric Investigation, 2008; 66: 1-7.

Fan D, Li S, Wang W, Tian G, Liu L, Wu S, Guo X, Liu Z. Sexual dysfunction and mode of delivery in Chinese primiparous women: a systematic review and meta-analysis. BioMedCentral Pregnancy and Childbirth, 2017; 17: 408.

Fugl-Meyer KS. Sexual disabilities and sexual problems. Swedish National Institute of Health, 2000; 199-216.

Ghorat F, Esfehani RJ, Sharifzadeh M, Tabarraei Y, Aghahosseini SS. Long term effect of vaginal delivery and cesarean section on female sexual function in primipara mothers. Electron Physician, 2017; 25(3): 3991-3996.

Glazener CMA. Sexual function after childbirth: women's experiences, persistent morbidity and lack of professional recognition. British Journal of Obstetrics and Gynaecology, 1997; 104: 330335.

Griffiths A, Watermeyer S, Sidhu K, Amso NN, Nix B. Female genital tract morbidity and sexual function following vaginal delivery or lower segment caesarean section. Journal of Obstetrics and Gynaecology, 2006; 26(7): 645-649.

Gun I, Dogan B, Ozdamar O. Long-and short-term complications of episiotomy. Turkisch Journal of Obstetrics and Gynecology, 2016;13(3): 144148.

Gungor S, Baser I, Ceyhan S, Karasahin E, Acikel $\mathrm{CH}$. Mode of delivery and subsequent long-term sexual function of primiparous women. International Journal of Impotence Research, 2007; 19(4): 358-365. 
Hannah ME, Hannah WJ, Hodnett ED, Chalmers B, Kung R, Willan A, et al. Term Breech Trial 3Month Follow-up Collaborative Group. Outcomes at 3 monthsfter planned cesarean vs planned vaginal delivery for breech presentation at term: the a international randomized Term Breech Trial. Journal of the American Medical Association, 2002; 10(287)14: 1822-1831.

Hannah ME, Whyte H, Hannah WJ, Hewson S, Amankwah K, Cheng M. Term Breech Trial Collaborative Group. Maternal outcomes at 2 years after planned cesarean section versus planned vaginal birth for breech presentation at term: the international randomized Term Breech Trial. American Journal of Obstetrics and Gynecology, 2004; 191(3): 917-927.

Hosseini L, Iran-Pour E, Safarinejad MR. Sexual function of primiparouswomen after elective cesarean section and normal vaginal delivery. Urology Journal, 2012; 9(2): 498-504.

Kadri N, McHichi Alami KH, McHakra Tahiri S. Sexual dysfunction in women: population based epidemiological study. Arch Womens Mental Health, 2002; 5: 59-63.

Kahramanoglu I, Baktiroglu M, Hamzaoglu K, Kahramanoglu O, Verit FF, Yucel O. The impact of mode of delivery on the sexual function of primiparous women: a prospective study. Archives of Gynecology and Obstetrics,2017; 295(4): 907-916.

Klein K, Worda C, Leipold H, Gruber C, Husslein P, Wenzl R. Does the mode of delivery influence sexual function after childbirth? Journal of Womens Health, 2009; 18: 1227-1231.

Klein MC, Gauthier RJ, Robbins JM, Kaczorowski J, Jorgensen SH, Franco ED. Relationship of episiotomy to perineal trauma and morbidity, sexual dysfunction, and pelvic floor relaxation. American Journal of Obstetrics and Gynecology, 1994; 171(3): 591-598.

McGahuey CA, Gelenberg AJ, Laukes CA, Moreno FA, Delgado PL. The Arizona Sexual Experience Scale (ASEX): Reliability and Validity. Journal of Sex and Marital Therapy, 2000; 26: 25-40.

Oberg K, Fugl-Meyer AR, Fugl-Meyer KS. On categorization and quantification of women's sexual dysfunctions: An epidemiological approach. International Journal of Impotence Research, 2004; 6: 261-269.

Pauls RN, Occhino JA, Dryfhout VL. Effects of pregnancy on female sexual function and body image: A prospective study. Journal of Sexual Medicine, 2008; 5: 1915-1922.
Rathfisch G, Dikencik BK, Kizilkaya Beji N, Comert N, Tekirdag AI, Kadioglu A. Effects of perineal trauma on postpartum sexual function. Journal of Advenced Nursing, 2010; 66(12): 2640-2649.

Rezaei N, Azadi A, Sayehmiri K, Valizadeh R. Postpartum Sexual Functioning and Its Predicting Factors among Iranian Women. Malaysian Journal of Medical Sciences, 2017: 24(1): 94-103.

Saydam BK, Demireloz Akyuz M, Sogukpinar N, Ceber Turfan E. Effect of delivery method on sexual dysfunction. Journal of Maternal Fetal Neonatal Medicine, 2017; 12: 1-5.

Shirvani MA, Nesami MB, Bavand M. Maternal sexuality after child birth among Iranian women. Pakistan Journal of Biological Sciences, 2010; 15(13): 385-389.

Signorello LB, Harlow BL, Chekos AK, Repke JT. Postpartum sexual functioning and its relationship to perineal trauma: a retrospective cohort study of primiparous women. American Journal of Obstetrics and Gynecology, 2001; 184: 881-888.

Thompson JF, Roberts CL, Currie M, Ellwood DA. Prevalence and persistence of health problems after childbirth: associations with parity and method of birth. Birth, 2002; 29: 83-94.

Turkey Demographic and Health Survey (2008) Hacettepe Institute of Population Studies, Ministry of Health, www.hips.hacettepe.edu.tr/tnsa2008/index.htm

Von Sydow K. Sexuality during pregnancy and after childbirth: A metacontent analysis of 59 studies. Journal of Psychosomatic Research, 1999; 47: 27-49.

West SL, D'Aloisio AA, Agans RP, Kalsbeek WD, Borisov NN, Thorp JM. Prevalence of low sexual desire and hypoactive sexual desire disorder in a nationally representative sample of US women. Archives of Internal Medicine, 2008; 14: 168(13): 1441-1449.

Woranitat W, Taneepanichskul S. Sexual function during the postpartum period. Journal of the Medical Association of Thailand, 2007; 90(9: 1744-1748.

World Health Organization (1985) Appropriate technology for birth. Lancet 2: 436-437.

World Health Organization. Sexual health: Working definitions (2012) www.who.International/reproductivehealth/gender/ sexual_health.html. 